\title{
HUBUNGAN PENGETAHUAN DAN PERILAKU PERAWAT DENGAN KEJADIAN HEMATOMA PASKA KATETERISASI JANTUNG
}

\author{
Junaidi $^{1}$, Maria Astrid ${ }^{2 *}$ \\ 1. Rumah Sakit X, Jakarta, Jakarta-Indonesia \\ 2. Keilmuan Keperawatan Medikal Bedah, STIK Sint Carolus, Jakarta-Indonesia
}

*Korespondensi: Maria Astrid | STIK Sint Carolus | astrid@ @stik-sintcarolus.ac.id

\begin{abstract}
Abstrak
Pendahuluan: Kateterisasi jantung adalah prosedur memasukkan catheter kedalam arteri femoralis atau arteri radialis yang didorong dari otot aorta desenden menuju arteri koronaria. Salah satu komplikasi dari kateterisasi jantung adalah hematoma. Penelitian ini bertujuan untuk mengetahui hubungan pengetahuan dan perilaku perawat dengan kejadian hematoma paska cateterisasi jantung.

Metode: Metode penelitian kuantitatif, desain penelitian deskriptif korelasi dengan pendekatan cross sectional. Sampel penelitian ini yaitu seluruh perawat di IMC, ICU dan Angiografi RS X sebanyak 37 orang. Teknik pengambilan sampel mengunakan purposive sampling dengan kriteria inklusi dan eksklusi yang sudah ditetapkan.. Alat pengumpulan data menggunakan instrumen kuesioner. Uji validitas dan reliabilitas kuesioner dilakukan pada 30 responden di RS Y Jakarta.

Hasil: Hasil analisis univariat, mayoritas responden berada pada rentang usia dewasa muda (83,8\%), masa kerja pada jenjang karir Perawat Klinik III (40,5\%), pendidikan DIII Keperawatan (78,4\%). Sebagian besar memiliki pengetahuan yang baik tentang prosedur paska kateterisasi jantung serta sebagian besar perawat memiliki perilaku yang baik tentang prosedur paska kateterisasi jantung (59,5\%). Hasil bivariate dengan uji chi- square didapatkan secara statistik ada hubungan pengetahuan perawat $(\mathrm{p}=0,001)$, dan perilaku perawat $(\mathrm{p}=0,000)$ dengan kejadian hematoma.

Kesimpulan: Diharapkan melalui seminar, workshop dan pelatihan perawat dapat memperoleh pengetahuan adekuat tentang prosedur paska kateterisasi jantung sehingga perawat dapat menjalankan prosedur sesuai dengan ketentuan yang ada, baik dalam pemantauan, kompresi dan pelepasan sheath.
\end{abstract}

Kata Kunci: Kateterisasi Jantung, Hematoma, Pengetahuan, Perilaku perawat.

Diterima 22 Agustus 2020; Accepted 30 Desember 2020

\section{PENDAHULUAN}

Tindakan kateterisasi jantung merupakan prosedur memasukkan catheter kedalam arteri femoralis atau arteri radialis yang didorong dari otot aorta desenden menuju arteri koronaria. Tujuannya untuk mengevaluasi anatomi dan adanya penyempitan pembuluh darah koroner. (Smeltzer \& Bare, 2008). Perawatan setelah menjalani prosedur kateterisasi jantung bertujuan untuk mengidentifikasi adanya iskemia atau infark pasca prosedur, mengidentifikasi efek dari zat kontras, adanya edema dan perdarahan pada area puncture serta mengidentifikasi adanya gangguan sirkulasi perifer. Semua tindakan ini diharapkan dapat mengidentifikasi masalah yang dialami pasien sesegera mungkin, untuk mencegah terjadi infeksi serta mempercepat penyembuhan kondisi pasien (Darliana, 2012).

Salah satu komplikasi dari kateterisasi jantung adalah hematoma. Hematoma adalah komplikasi yang sering dengan tanda tampak memar di daerah tusukan. Penatalaksanaannya dengan menekan secara manual atau mekanik. Efek samping dari kejadian hematoma adalah ketidaknyamanan pasien, dan nyeri disekitar area hematoma (Pintaningrum, 2016). Penelitian Abdul-Monim Batiha (2016) telah memberikan bukti bahwa perdarahan post kateterisasi jantung, lebih berbahaya, penelitian dilakukan pada 10.974 pasien yang dilakukan kateterisasi jantung, disebutkan bahwa perdarahan paska tindakan merupakan prediktor signifikan di rumah sakit sebagai penyebab kematian.

Di Indonesia, Rumah sakit Cipto Mangunkusumo Jakarta telah melakukan tindakan kateterisasi jantung 650 tindakan pada tahun 2006 dan 1125 tindakan pada tahun 2007. (Darliana, 2012). Rumah Sakit X yang memiliki fasilitas cathlab tercatat dari tahun 2015 sampai 2017 total selama 3 tahun melakukan tindakan katetrrisasi sebanyak 654 tindakan. Pada tahun 2015 terdapat 201 tindakan kateterisasi jantung, tahun 2016 total 210 tindakan, pada tahun 2017 sebanyak 243 tindakan. Data yang diperoleh peneliti di Ruang Cathlab pada tahun 2015 terjadi 8 hematome selama 1 tahun, tahun 2016 terjadi 6 hematome dan pada tahun 2017 terjadi 7 hematome (5 femoralis dan 2 radialis) selama 1 tahu atau 17,01\% dari total tindakan 
kateterisasi (Data rekam medis Angiografi RS X Jakarta).

Di rumah sakit X menurut Standard Operasional Prosedur (SPO) perawatan paska kateterisasi (2017) yaitu memberitahu hasil tindakan, pemeriksaan tanda - tanda vital, komplikasi dan jadwal aff sheath. Sheat adalah akses untuk memasukkan alat kedalam pembuluh darah untuk melihat anatomi dari jantung. Dalam SPO di RS X (2017), paska kateterisasi jantung perawat menjelaskan prosedur perawatan untuk menghindari kejadian hematoma seperti area yang terpasang sheath tidak boleh ditekuk $90^{\circ}$ atau tidak boleh terlalu sering ditekuk diarea lipatan dekat tusukan puncture dan pasien harus bedrest. Hasil wawancara dengan kepala ruang ICU/IMC di RS X masih ditemukan perawat yang belum memahami tentang perawatan pasien paska kateterisasi jantung, seperti mengobservasi arteri femoralis yang terpasang sheath, pentingnya pemberian edukasi terhadap pasien paska kateterisasi masih kurang dipahami oleh perawat, sosialisasi tentang SPO perawatan paska kateterisasi tidak berkala, belum adanya pelatihan perawatan paska kateterisasi jantung dan perilaku perawat saat mengobseravi masih ada yang baik dan kurang. Melihat fenomena diatas peneliti tertarik untuk melakukan penelitian tentang hubungan pengetahuan dan perilaku perawat dengan kejadian hematoma paska kateterisasi jantung di RS X Jakarta.

\section{METODE}

Populasi pada penelitian ini adalah seluruh perawat di IMC, ICU dan Angiografi RS X. Teknik pengambilan sampel yang digunakan adalah tekhnik purposive sampling dan jumlah sampel sebanyak 37 responden. Kriteria inklusi penelitian ini adalah seluruh perawat IMC, ICU dan Angiografi RS X yang sudah pernah mendapatkan sosialisasi perawatan paska kateterisasi jantung. Kriteria eksklusi dalam penelitian ini yaitu kepala ruangan, perawat yang sedang study, perawat oriented dan perawat kontrak kerja. Penelitian dilakukan di RS X Jakarta di ruang IMC, ICU dan Angiografi. Penelitian dilakukan pada bulan Mei sampai Agustus 2018. Analisis data yang dilakukan terdiri dari analisa univariat dan bivariat. Analisa univariat digunakan untuk menghasilkan distribusi frekuensi dan persentase hasil data demografi (usia, lama kerja, pendidikan), variabel kejadian hematoma paska kateterisasi jantung, pengetahuan dan perilaku. Analisis bivariat digunakan untuk mengetahui hubungan dua variabel, menggunakan analisis uji statistic korelasi dengan analisis Chi square.

\section{HASIL}

\section{Hasil Univariat}

Distribusi data demografi responden

Tabel 1 Distribusi Responden Berdasarkan Data Demografi $(n=37)$

\begin{tabular}{ccc}
\hline Variabel & $\mathbf{N}$ & $\mathbf{\%}$ \\
\hline Usia & 31 & $\mathbf{9 3 , 8}$ \\
Dewasa Muda & 6 & 16,2 \\
Dewasa Menengah & & \\
Lama Kerja & 14 & 37,8 \\
PK I & 8 & 21,6 \\
PK II & 15 & $\mathbf{4 0 , 5}$ \\
PK III & 29 & $\mathbf{7 8 , 4}$ \\
Pendidikan & 8 & 21,6 \\
D III & 87 & 100 \\
Ners & 37 &
\end{tabular}

Sumber : data primer yang diolah

Pada tabel 1 terlihat bahwa berdasarkan karakteristik demografi, mayoritas responden berada pada rentang usia dewasa muda (21-40 tahun), berpendidikan D3 Keperawatan dan sebagian besar perawat memiliki masa kerja pada jenjang karir Perawat Klinik III.

Distribusi kejadian hematoma paska kateterisasi jantung 
Tabel 2. Distribusi Responden Berdasarkan kejadian hematoma paska kateterisasi jantung ( $n=37$ )

\begin{tabular}{ccc} 
Hematoma & F & \% \\
\hline Tidak Ada & $\mathbf{2 4}$ & $\mathbf{6 4 , 9}$ \\
Ada & 13 & 35,1 \\
\hline Total & 37 & 100 \\
\hline
\end{tabular}

Sumber : data primer yang diolah

Berdasarkan tabel 2 dapat disimpulkan bahwa berdasarkan kejadian hematoma paska kateterisasi jantung, sebagian besar pasien tidak mengalami hematoma paska kateterisasi jantung.

Distribusi pengetahuan perawat

Tabel 3. Distribusi pengetahuan tentang prosedur paska kateterisasi jantung $(n=37)$

\begin{tabular}{ccc}
\hline Pengetahuan & F & \% \\
\hline Baik & $\mathbf{2 4}$ & $\mathbf{6 4 , 9}$ \\
Cukup & 13 & 35,1 \\
\hline Total & 37 & 100 \\
\hline Sumber : data primer yang diolah & &
\end{tabular}

Pada tabel 3 terlihat bahwa berdasarkan pengetahuan perawat tentang prosedur paska kateterisasi jantung sebagian besar perawat memiliki pengetahuan yang baik tentang prosedur paska kateterisasi jantung $(64,9 \%)$, dan masih ada $35,1 \%$ perawat yang pengetahuannya masih dalam kategori cukup.

\section{$\underline{\text { Gambaran Perilaku Perawat }}$}

Tabel 4. Distribusi Frekuensi Perilaku Perawat Tentang Prosedur Paska Kateterisasi Jantung (n=37)

\begin{tabular}{ccc} 
Perilaku & F & $\%$ \\
\hline Baik & $\mathbf{2 2}$ & $\mathbf{5 9 , 5}$ \\
Kurang & 15 & 40,5 \\
\hline Total & 37 & 100 \\
\cline { 2 - 3 } Sumber: data primer yang diolah & &
\end{tabular}

Berdasarkan tabel 4 dapat disimpulkan bahwa sebagian besar responden memiliki perilaku yang baik terkait prosedur paska kateterisasi jantung $(59,5 \%)$ sedangkan 40,5\% lainnya masih memiliki perilaku yang kurang.

\section{Hasil Bivariat}

Hubungan antara pengetahuan dan kejadian hematoma

Tabel 5. Hubungan pengetahuan dengan kejadian hematoma Paska Katetrisasi Jantung Di RS X Jakarta

\begin{tabular}{cccccccc}
\multicolumn{1}{c}{ Tidak Ada } & \multicolumn{2}{c}{ Ada } & \multirow{2}{*}{ Total } & P Value \\
\hline \multirow{2}{*}{ Pengetahuan } & F & $\%$ & F & $\%$ & & & \\
& 20 & 83,3 & 4 & 16,7 & 24 & 100 & $\mathbf{0 . 0 0 1}$ \\
\hline Baik & & &
\end{tabular}




\begin{tabular}{lcccccc}
\hline Cukup & 4 & 30,8 & 9 & 69,2 & 13 & 100 \\
\hline Total & 24 & 64,9 & 13 & 35,1 & $\mathbf{3 7}$ & $\mathbf{1 0 0}$ \\
\hline
\end{tabular}

Sumber : data primer yang diolah

Pada table 5 didapatkan hasil bahwa perawat yang memiliki pengetahuan baik mayoritas $(83,3 \%)$ tidak menimbulkan hematoma pada pasien paska kateterisasi jantung, sedangkan responden yang memiliki pengetahuan cukup sebagian besar $(69,2 \%)$ menimbulkan hematoma paska kateterisasi jantung. Hasil analisa statistik dengan menggunakan Chi Square Test didapatkan $P$ Value $=0,001<\alpha=0,05$, dengan demikian dapat disimpulkan bahwa secara statistic ada hubungan pengetahuan perawat tentang prosedur paska kateterisasi jantung dengan kejadian hematoma pada pasien paska kateterisasi jantung.

Hubungan antara perilaku dan kejadian hematoma

Tabel 6. Hubungan Perilaku Dengan Kejadian Hematoma Paska Katetrisasi Jantung Di RS X Jakarta $(\mathrm{n}=37)$

\begin{tabular}{ccccccc}
\hline \multirow{2}{*}{ Perilaku } & \multicolumn{2}{c}{ Tidak Ada } & \multicolumn{2}{c}{ Ada } & Total & P Value \\
& F & $\%$ & F & $\%$ & & \\
\hline Baik & 22 & 100 & 0 & 0 & 22 & $100 \quad \mathbf{0 , 0 0 0}$ \\
Kurang & 2 & 13,3 & 13 & 86,7 & 15 & 100 \\
\hline Total & 24 & 64,9 & 13 & 35,1 & 37 & 100 \\
\hline
\end{tabular}

Berdasarkan tabel 6 didapatkan hasil bahwa perawat yang memiliki perilaku baik semuanya (100\%) tidak menimbulkan hematoma paska kateterisasi jantung, sedangkan responden yang memiliki perilaku cukup sebagian besar $(86,7 \%)$ menimbulkan hematoma paska kateterisasi jantung. Hasil analisa statistik dengan menggunakan Chi Square Test didapatkan $P$ Value $=0,000<\alpha=0,05$, dengan demikian dapat disimpulkan bahwa secara statistic ada hubungan yang signifikan antara perilaku perawat terhadap kejadian hematoma paska kateterisasi jantung.

\section{PEMBAHASAN}

Pada table 1 terlihat bahwa berdasarkan karakteristik demografi, mayoritas responden berada pada rentang usia dewasa muda (21-40 tahun), berpendidikan D3 Keperawatan dan sebagian besar perawat memiliki masa kerja pada jenjang karir Perawat Klinik III. Perawat yang berdinas di RS X Jakarta merupakan perawat yang masih dalam usia produktif. Kebijakan RS X untuk berkembang dengan merekrut perawat pada saat lulus pendidikan dan perawat yang berpengalaman. Responden dalam penelitian ini adalah perawat yang bertugas di ruang ICU, intermediet dan angiografi. Kebijakan RS X adalah bahwa perawat ruang khusus membutuhkan keterampilan khusus sehingga perawat yang bertugas di ruang khusus merupakan perawat yang sebagian besar merupakan perawat yang sudah memiliki pengalaman baik dirumah sakit sebelumnya, maupun dirumah sakit yang sama. Namun pada penelitian ini terdapat 37,8\% responden dengan Perawat Klinik I. Hal ini karena RS X sedang kekurangan tenaga (SDM) akibat dari rotasi antar rumah sakit sehingga perawat dengan PK I direkrut di ruang khusus. Mayoritas perawat pelaksana di RS X berpendidikan Diploma Keperawatan. Oleh karena itu RS X Jakarta melakukan program pendidikan berkelanjutan untuk perawat pelaksana yang masih berpendidikan DIII untuk melanjutkan ke jenjang pendidikan Ners.

Tabel 2 memperlihatkan kejadian hematoma paska kateterisasi jantung, dimana sebagian besar pasien tidak mengalami hematoma paska kateterisasi jantung. Hematoma merupakan merupakan salah satu komplikasi vaskular yang paling banyak dilaporkan dan berpotensi menimbulkan komplikasi serius paska kateterisasi jantung (Jones, 2002 dalam Sari, 2017). Dalam mencegah timbulnya komplikasi vaskular pada 
pasien post kateterisasi jantung, RS X Jakarta memiliki standar prosedur operasional (SOP) yang baku. Pada penelitian ini juga ditemukan $35,1 \%$ pasien yang mengalami hematoma paska kateterisasi jantung karena lupa menekuk bagian yang terpasang sheath atau luka tusukan puncture.

Pada tabel 3 terlihat bahwa berdasarkan pengetahuan perawat tentang prosedur paska kateterisasi jantung sebagian besar perawat memiliki pengetahuan yang baik tentang prosedur paska kateterisasi jantung (64,9\%), dan masih ada 35,1\% perawat yang pengetahuannya masih dalam kategori cukup. Perawat dalam penelitian ini memiliki pengetahuan yang baik dikarenakan perawat-perawat yang bertugas pada area-area penelitian merupakan perawat yang pernah mendapatkan sosialisasi dari Diklat RS/seminar/workshop/pelatihan dalam menangani pasien paska kateterisasi jantung. Melalui pelatihan dan pendidikan khusus baik formal ataupun non formal para perawat mendapatkan pengetahuan yang lebih banyak tentang prosedur paska kateterisasi jantung. Selain itu, dalam penelitian ini tidak ada perawat dengan pengetahuan kurang karena sudah sering diberikan briefing tentang perawatan paska kateterisasi oleh kepala bagian dan adanya SOP yang berlaku. Di RS X penyelenggaraan pelatihan formal tentang aff sheath hanya pada dilakukan untuk petugas angiografi, sedangkan perawat IMC dan ICU mendapatkan sharing penanganan perawatan pasien paska kateterisasi Jantung pada saat pre konferensi atau siang clinic oleh kepala bagian/Koordinator.

Tabel 4 dapat disimpulkan bahwa sebagian besar responden memiliki perilaku yang baik terkait prosedur paska kateterisasi jantung (59,5\%) sedangkan 40,5\% lainnya masih memiliki perilaku yang kurang. Tingginya angka perilaku baik pada penelitian ini disebabkan karena sebagian besar perawat sudah berpengalaman dalam melakukan prosedur paska kateterisasi jantung. Sesuai dengan teori Notoatmodjo (2012) yang menyatakan bahwa pengetahuan merupakan domain tertinggi dalam pembentukan perilaku. Namun pada penelitian ini masih terdapat perilaku perawat yang kurang karena masih ada perilaku perawat yang lalai, tidak terlalu menghiraukan dan menganggap hal biasa tentang pentingnya perawatan paska kateterisasi jantung.

Pada table 5 didapatkan hasil bahwa perawat yang memiliki pengetahuan baik mayoritas $(83,3 \%)$ tidak menimbulkan hematoma pada pasien paska kateterisasi jantung, sedangkan responden yang memiliki pengetahuan cukup sebagian besar $(69,2 \%)$ menimbulkan hematoma paska kateterisasi jantung. Hasil analisa statistik dengan menggunakan Chi Square Test didapatkan $P$ Value $=0,001<\alpha=0,05$, dengan demikian dapat disimpulkan bahwa ada hubungan pengetahuan perawat tentang prosedur paska kateterisasi jantung dengan kejadian hematoma pada pasien paska kateterisasi jantung. Notoatmodjo (2012) menyatakan bahwa pengetahuan didapatkan dari sekumpulan informasi yang saling terhubung secara sistematik sehingga memiliki makna. Informasi diperoleh dari data yang sudah diolah sehingga mempunyai arti. Kemudian data ini akan dimiliki seseorang dan menjadi memori yang tersimpan diotaknya. Ketika manusia dihadapkan pada suatu masalah maka informasi yang tersimpan tadi dan terkait dengan permasalahnya tersebut akan saling terhubung dan tersusun secara sistematik sehingga memiliki model untuk memahami atau memiliki pengetahuan yang terkait dengan permasalah yang sedang dihadapinya. Komplikasi vaskular yang paling sering terjadi paska kateterisasi jantung adalah hematoma. Hematoma terjadi karena area akses penutupan tidak tertutup dengan baik dan terjadi akumulasi darah sekitar jaringan. Hematoma yang besar dan luas menimbulkan rasa ketidaknyamanan pada pasien dan berpotensi menjadi false aneurysms (Lundin (1998), dalam Sari, 2017). Penelitian Darliana di Aceh (2012) mengungkapkan pentingnya perawatan setelah menjalani prosedur kateterisasi jantung yang bertujuan untuk mengidentifikasi adanya iskemia atau infark pasca prosedur, mengidentifikasi efek dari zat kontras, adanya edema dan perdarahan pada area puncture serta mengidentifikasi adanya gangguan sirkulasi perifer. Semua tindakan ini diharapkan dapat mengidentifikasi masalah yang dialami pasien sesegera mungkin, mencegah terjadi infeksi serta mempercepat penyembuhan kondisi pasien. Oleh karena itu perawatan pasien secara komprehensif diperlukan baik sebelum, selama dan setelah prosedur kateterisasi jantung (Underhill, 2005;Huddak \& Gallo, 2005., dalam Darliana (2012). Pengetahuan yang baik pada prosedur paska kateterisasi terutama saat pelepasan sheath akan sangat berguna untuk menciptakan output suatu prosedur yang baik dan tidak menimbulkan komplikasi. Di RS X masih adanya kejadian hematome sehingga perlu meningkatkan pengetahuan perawat untuk mengurangi resiko terjadinya komplikasi seperti hematoma paska kateterisasi jantung.

Pada tabel 6 didapatkan hasil bahwa perawat yang memiliki perilaku baik semuanya (100\%) tidak menimbulkan hematoma paska kateterisasi jantung, sedangkan responden yang memiliki perilaku cukup sebagian besar $(86,7 \%)$ menimbulkan hematoma paska kateterisasi jantung. Hasil analisa statistik dengan 
menggunakan Chi Square Test didapatkan $P$ Value $=0,000<\alpha=0,05$, dengan demikian dapat disimpulkan bahwa secara statistic ada hubungan yang signifikan antara perilaku perawat terhadap kejadian hematoma paska kateterisasi jantung. Perilaku adalah suatu kegiatan atau aktifitas organisme (makhluk hidup) yang bersangkutan. Tiap individual adalah unik, dimana mengandung arti bahwa manusia yang satu berbeda dengan manusia yang lain dan tidak ada dua manusia yang sama persis dimuka bumi ini, walaupun ia dilahirkan kembar. Manusia mempunyai ciri - ciri, sifat, watak, tabiat, kepribadian, dan motivasi tersendiri yang membedakannya dari manusia lainnya. Perbedaan pengalaman yang dialami individu pada masa silam dan cita-citanya kelak dikemudian hari, menentukan perilaku individu dimasa kini yang berbeda beda pula (Notoatmodjo, 2012). Menurut peneliti, dalam melaksanakan pemantauan tersebut perawat harus memiliki perilaku yang baik dalam melakukan prosedur. Perilaku merupakan respon individu terhadap sebuah rangsangan atau stimulus dan perilaku tercermin dalam sebuah aktivitas yang bisa diamati ataupun tidak bisa diamati oleh pihak lain. Perilaku perawat yang mampu menjalankan prosedur paska kateterisasi jantung dengan baik akan meminimalkan terjadinya komplikasi vaskular paska kateterisasi jantung. Perawat dengan pengetahuan yang baik dan perilaku yang baik, diharapkan keselamatan pasien yang menjalani kateterisasi jantung dapat lebih dioptimalkan lagi. Di RS X masih ditemukan adanya perawat yang acuh dan kurang menghiraukan pentingnya perawatan pasien paska kateterisasi jantung.

\section{KESIMPULAN}

Pada penelitian ini disimpulkan bahwa terdapat hubungan bermakna antara pengetahuan dan perilaku perawat dengan kejadian hematoma paska kateterisasi jantung. Mengingat besarnya dampak yang dapat ditimbulkan akibat adanya hematoma paska kateterisasi jantung, disarankan bagi para perawat dapat menjalankan prosedur paska kateterisasi jantung sesuai dengan ketentuan yang ada, baik dalam pemantauan, kompresi dan pelepasn sheath.

\section{REFERENSI}

Batiha. (2016). Predictors of Complications after Sheath Coronary Syndrome.

Darliana. (2012). Treatment of Patients Undergoing Cardiac Catheterization Procedures. Idea Nursing Journal. Vol. III No. 3

Hudak \& Gallo (2005). Keperawatan Kritis, edisi VI. Jakarta: EGC

Jones \& Mccutcheon. (2002). Effectiveness of Mechanical. American Journal of Critical care, 155-162.

Lundin,L.., Sargent,T., \& Burke,L. (1998). Research Utilization and improvement in outcomes after diagnostic cardiac catheterization. Critical care nurse, 18(5),30-1,34-9. Retrieved from http://www.ncbi.nlm.nih.gov/pubmed/9934047

Notoadmodjo. (2012). Promosi Kesehatan dan Perilaku Kesehatan. Jakarta: Rineka Cipta.

Pintaningrum. (2016). Komplikasi Intervensi Koroner Perkutan. Jurnal Kedokteran 2016, 5(4): 32-37

Sari; Arifin, Fatimah. (2017). Perbandingan Hematoma Paska Kateterisasi Jantung Berdasarkan Penekanan Bantal Pasir dan Cold Pack. Jurnal Pendidikan Keperawatan Indonesia. Volume 2, No.2.

Smeltzer, \& Bare. (2008). Medical Surgical Nursing. Nursing Brunner-Suddarth, 8th Edition. Philadelphia: Mosby Company.

Underhill, Woods, Froelicher,.\& Halpenny. (2005). Cardiac Nursing. $5^{\text {th }}$ Edition, Lippincott William \& Walkins. 